\title{
LOCALIZATION OF POLLUTION OF SOILS AND GROUNDWATERS WITHIN THE INFLUENCE OF THE TECHNOGENIC SWITCHES
}

\author{
Zhomyruk R.V.
}

National University of Water and Environmental Engineering (NUWEE), Ph.D., Associate Professor, Department of Automation, Electrical Engineering and Computer-Integrated Technologies, Ukraine

Malanchuk E.Z.

National University of Water and Environmental Engineering (NUWEE), Doctor of Engineering, Professor,, Department of Automation, Electrical Engineering and Computer-Integrated

Technologies, Ukraine

Stets S.E.

National University of Water and Environmental Engineering

(NUWEE), Ph.D., Associate Professor, Department of Automation, Electrical Engineering and Computer-Integrated Technologies, Ukraine

Khrystiuk A.O.

National University of Water and Environmental Engineering (NUWEE), Ph.D., Associate Professor, Department of Automation, Electrical Engineering and Computer-Integrated Technologies, Ukraine

\section{Summary}

This scientific article contains research material to address the problem of the storage of man-made wastes and reduce their negative impact on the environment. The results of experimental and field studies of the storage area of technogenic phosphogypsum dumps and the impact of dumps on the environment are presented. Recommendations for environmentally sound storage and disposal of waste are given. The recommendations on the design of protective drainage for the interception of highly mineralized waters with the aim of preventing contamination of soil and groundwater in the area of technogenic dumps are given. 


\section{Introduction}

Ensuring the ecologically safe existence of all natural objects is one of the major problems of our time. This provision is in no doubt, especially as the adequate solution of this issue and its subsequent implementation will provide not only comfortable living conditions and optimal sanitary and hygienic conditions of their production activities, but also the very existence of the biosphere. That is why environmental security is now regarded as an integral element of national security, which is very relevant for all countries of the world [1].

Ukraine is no exception in this regard, and environmental problems affecting all its regions are no less, and sometimes more acute, than in other countries of the world, as the current state of the environment in our country is beginning to take on negative properties, becoming immediate. a source of threat to the biosphere itself, as well as to the health and even life of its citizens. The main reason for this situation is all the same: excessive man-made load on natural objects without the proper level of environmental responsibility of those who control the development of production, which is increasing the current economic state of the state. Due to this, the rate of environmental degradation, and not only within the direct impact of specific enterprises, begins to exceed (and in some areas has already exceeded) the adaptive capacity of its components [2].

Given the scale and significance of the problem of industrial waste in Ukraine, there is a need to justify the parameters of localization of groundwater contamination and develop engineering methods aimed at improving the environmental situation and reducing the incidence of population within the impact of waste heaps of various industries.

\section{Object and objectives of the study}

The object of the research is phosphogypsum dumps near the production site of Rivneazot PJSC. They are a serious threat to the residents of Rivne and the surrounding villages, as well as the entire Goryn river basin. It is a waste of the fourth class of danger, which is represented mainly by phosphorus oxides accumulated in phosphogypsum dumps.

Laboratory studies of phosphogypsum have shown that in terms of dry matter, it contains $94 \%$ CaSO4, 1.8 undigested apatite, 1.8 phosphoric acid, 0.22 silicic acid, 1.92 insoluble residue, up to $1 \%$ iron and aluminum oxides. [3]. 
The dumps cover an area of 58 hectares and their total amount is 15.3 million tons [4]. The solution to the problem of industrial waste disposal in Rivne region depends to a large extent on how successfully this problem will be solved at this site.

For these environmentally hazardous dumps and most similar sites, it is common that the waste is stored outdoors. Due to the filtration of precipitation through this object, harmful substances get into the ground water, which leads to contamination of the soil adjacent to the object territory. For a long time such storage, not only dumps or waste heaps of mining, but also adjacent territory become environmentally dangerous. This factor should be taken into account when designing measures that will ensure environmentally-safe operation of open storage facilities for mining and other industries.

Therefore, finding ways to prevent contamination of soil and groundwater from the effects of phosphogypsum dumps, processing and disposal of phosphogypsum are important and urgent tasks.

\section{Results of experimental and field studies.}

The analysis of the object of study, which included topographic surveying, determination of chemical, mechanical composition of soil and groundwater, water-physical properties of soil of the adjacent territory was carried out in the work. $[4,5]$. The level of morbidity of the population living in the territories adjacent to the waste heaps is analyzed [6]. As a result of the studies, the degree of soil and groundwater contamination was determined.

It has been confirmed that phosphogypsum dumps cause soil and groundwater contamination that spreads towards the river. This is evidenced by the nature of the distribution of pollutants in the soil: less value of the mass fraction of dry salt residue in the upper soil layers (depth 1-3 m) and greater value at the level of groundwater deposition (depth $>3 \mathrm{~m}$ ) [5].

According to experimental studies, not only the phosphogypsum dumps themselves, but also the adjacent territory are the source of contamination. Due to the wind erosion of the dumps and the transfer of groundwater contamination, the soil contamination in the radius of $1 \mathrm{~km}$ around the dumps exceeded the limit values. Nitrate content in the soil exceeds the maximum permissible concentration and ranges from 30 to $90 \mathrm{mg} / \mathrm{dm}^{3}$ (MPC - $45 \mathrm{mg} / \mathrm{dm}^{3}$ ). The content of chromium in the soil is $3.0-6.0 \mathrm{mg} / \mathrm{dm}^{3}$ (MPC $-1.0 \mathrm{mg} / \mathrm{dm}^{3}$ ) [7]. The content of 
manganese in groundwater within the study area in all samples exceeds the MPC $\left(0.1 \mathrm{mg} / \mathrm{dm}^{3}\right)$. The area with solid manganese content in groundwater of $50-300 \mathrm{mg} / \mathrm{dm}^{3}$ is allocated directly on the territory of the landfill site. Iron content in groundwater - is in the range of $2000-1000 \mathrm{mg} / \mathrm{kg}$ (MPC $\left.-0.3 \mathrm{mg} / \mathrm{dm}^{3}\right)$. In groundwater, petroleum products were detected and amounted to $4.3 \mathrm{mg} / \mathrm{dm}^{3}$ (MPC - 0.3 $\left.\mathrm{mg} / \mathrm{dm}^{3}\right)$. The content of lead, zinc, copper, cadmium, nickel, cobalt, nitrite in groundwater is generally higher than the MPC $[8,9]$. The results of chemical analysis of water samples taken from the site show the mineralization of water $8.3 \mathrm{mg} / \mathrm{dm}^{3}$ [5].

Analyzing the results of the research, we can conclude that in the experimental site there is filtration of highly mineralized water from the territory of phosphogypsum dumps, which leads to contamination of soil, groundwater and waters of the Goryn river [10]. As a consequence, it has a negative impact on the health of the population: the incidence rate in the phosphogypsum waste heaps has increased by 30\% compared to 1999 and 2019 [6].

Given the results of experimental and full-scale studies, finding ways to prevent contamination within the impact of man-made dumps is an extremely important task.

\section{Recommendations for environmentally safe storage and dis- posal of phosphogypsum dumps}

On the basis of full-scale, experimental researches and mathematical modeling, recommendations for environmentally safe storage and disposal of phosphogypsum dumps [13] have been developed, which include three stages:

engineering scheme for intercepting contaminated water from the territory of phosphogypsum dumps;

coating of phosphogypsum dumps with a protective polyethylene film, followed by powdering with a fertile soil layer and planting;

processing of phosphogypsum into building materials.

Engineering scheme for intercepting contaminated water from the territory of phosphogypsum dumps.

The scheme is presented in Fig. 1. In the area around the dumps it is proposed to have a collector-drainage network $(1,2)$ which will intercept and divert contaminated groundwater to treatment facilities (14) of Rivneazot PJSC, which are located at a distance of $5 \mathrm{~km}$ from 
the territory of the object of study. In order to intercept contaminated water coming from the territory of the phosphogypsum dumps, it is proposed to arrange hunting channels (3) along the perimeter of the object. From the feed channels, the solution is fed to the pump station (5) into the storage pool (7), which is located on the dumps themselves (4). The pumping station can operate in two modes: main and emergency. The main mode is the supply of water to the sump basin, the emergency mode is connected with the possible damage to the sump basin, then the contaminated water is supplied from hunting channels directly to the treatment facilities of Rivneazot PJSC.

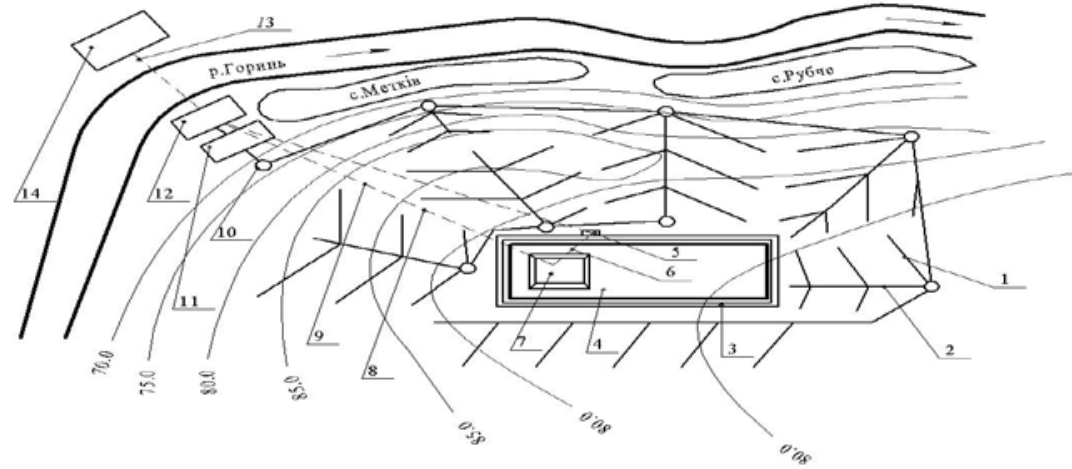

Fig. 1. Engineering network of contamination localization within the impact of phosphogypsum dumps: 1 - drains; 2 - collector; 3 - hunting channels; 4 - dumps of phosphogypsum; 5 - pumping station; 6,13 - pressure pipeline; 7 - storage pool; 8 , 9 - pressureless pipeline; 10 - drainage well; 11 - precast pool; 12 - pumping station; 14 - treatment plants

To calculate the parameters of the drainage-collector network for intercepting highly mineralized water coming from the phosphogypsum dumps, it was used by O. Oliynyk [14]. The basis of the calculation is a scheme of a bounded layer, which in the plan has one external rectilinear border (Fig. 2). To satisfy the boundary condition on the power circuit $H=H_{1}=$ const at $X=0$, when positioned on the right side at a distance $\mathrm{L}$ from the axis of the runoff, it is necessary to place a symmetric source of equal intensity $q$ on the left distance from that axis at the same distance. Thus, in order to find a solution to this problem it is necessary to summarize the solutions for the drain and the source [15]. We limit ourselves to adding up the equation for 
a two-layer soil, given that by replacing the corresponding coefficients it is easy to get a solution for soils with more layers.

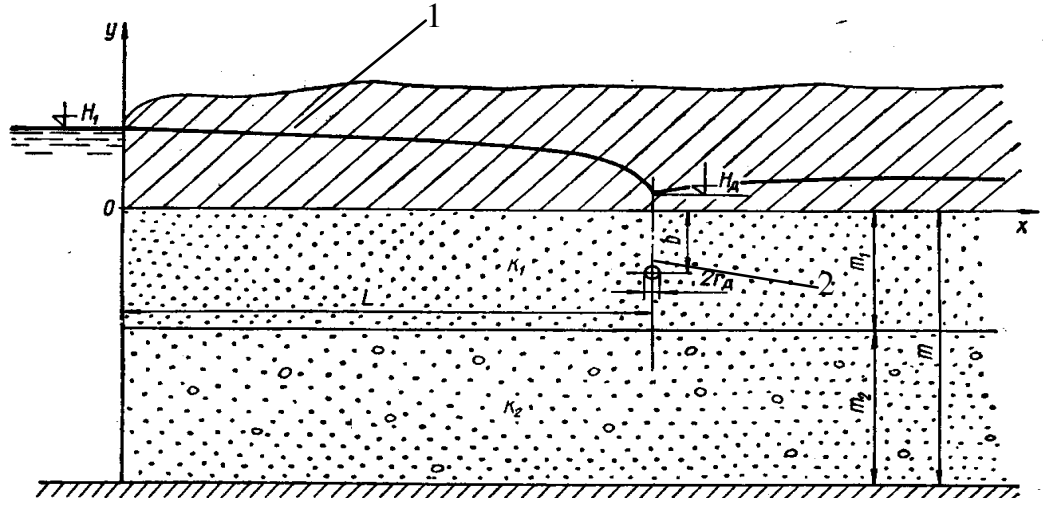

Fig. 2. The design scheme of unilateral drainage inflow: 1 - curve of depression; 2 drainage

Since the solution of the problem for the runoff placed at the point with coordinates $(L,-b)$ and having a flow $q$, is expressed by the equation.

$$
\begin{aligned}
& H(x, y)=\frac{q}{4 \pi r_{1}}\left\{\ln \left[(x-L)^{2}+(y+b)^{2}\right]+\ln \left[(x-L)^{2}+(y-b)^{2}\right]\right\}+ \\
& +\frac{q}{4 \pi r_{1}} \sum_{n=1}^{\infty} c_{n}^{\prime}\left\{\ln \left[(x-L)^{2}+\left(y+2 n m_{0}-b\right)^{2}\right]+\ln \left[(x-L)^{2}+\left(y+2 n m_{0}+b\right)^{2}\right]+\right. \\
& \left.+\ln \left[(x-L)^{2}+\left(y-2 n m_{0}+b\right)^{2}\right]+\ln \left[(x-L)^{2}+\left(y-2 n m_{0}-b\right)^{2}\right]\right\}+C_{1}
\end{aligned}
$$

where $m_{0}$ is the total largest divisor of $m_{1}$ and $m_{2}$

The solution of the problem for the source located at the point $(-L$, $-b$ ) and having a flow rate of $-\mathrm{q}$ will be as follows

$$
\begin{aligned}
& H(x, y)=-\frac{q}{4 \pi r_{1}}\left\{\ln \left[(x+L)^{2}+(y+b)^{2}\right]+\ln \left[(x+L)^{2}+(y-b)^{2}\right]\right\}- \\
& -\frac{q}{4 \pi r_{1}} \sum_{n=1}^{\infty} c_{n}^{\prime}\left\{\ln \left[(x+L)^{2}+\left(y+2 n m_{0}-b\right)^{2}\right]+\ln \left[(x+L)^{2}+\left(y+2 n m_{0}+b\right)^{2}\right]+\right. \\
& \left.+\ln \left[(x+L)^{2}+\left(y-2 n m_{0}+b\right)^{2}\right]+\ln \left[(x+L)^{2}+\left(y-2 n m_{0}-b\right)^{2}\right]\right\}+C
\end{aligned}
$$

Summing up expressions (1) and (2), we find the final solution of the problem: 


$$
\begin{aligned}
& H(x, y)=\frac{q}{4 \pi r_{1}}\left\{\ln \frac{\left[(x-L)^{2}+(y+b)^{2}\right]\left[(x-L)^{2}+(y-b)^{2}\right]}{\left[(x+L)^{2}+(y+b)^{2}\right]\left[(x+L)^{2}+(y-b)^{2}\right]}+\right. \\
& +\sum_{n=1}^{\infty} c_{n}^{\prime} \ln \frac{\left[(x-L)^{2}+\left(y+2 n m_{0}-b\right)^{2}\right]\left[(x-L)^{2}+\left(y+2 n m_{0}+b\right)^{2}\right]}{\left[(x+L)^{2}+\left(y+2 n m_{0}-b\right)^{2}\right]+\left[(x+L)^{2}+\left(y+2 n m_{0}+b\right)^{2}\right]} \times \\
& \times \frac{\left[(x-L)^{2}+\left(y-2 n m_{0}+b\right)^{2}\right]\left[(x-L)^{2}+\left(y-2 n m_{0}-b\right)^{2}\right]}{\left[(x+L)^{2}+\left(y-2 n m_{0}+b\right)^{2}\right]\left[(x+L)^{2}+\left(y-2 n m_{0}-b\right)^{2}\right]}+C
\end{aligned}
$$

In order to satisfy the condition $H=H_{1}$ at $X=0$, the constant $C$ must be taken to be equal to $H_{l}$. The pressure $H_{D}$. on the contour of the tubular drain with radius $r_{D}$ is determined from the expression (3), substituting into it $x=L-r_{D}$ and $y=-b$ :

$$
\begin{aligned}
H_{\text {Д }} & =\frac{q}{4 \pi r_{1}}\left\{\ln \frac{r_{\text {Д }}^{2}\left(r_{\text {Д }}^{2}+4 b^{2}\right)}{\left(2 L-r_{\text {Д }}\right)^{2}\left[\left(2 L-r_{\text {Д }}\right)+4 b^{2}\right]^{+}}\right. \\
+\sum_{n=1}^{\infty} c^{\prime}{ }_{n} \ln \frac{\left[r_{\text {Д }}^{2}+4\left(n m_{0}-b\right)^{2}\right]\left(r_{\text {Д }}^{2}+4 n^{2} m_{0}^{2}\right)^{2}}{\left[\left(2 L-r_{\text {Д }}\right)^{2}+4\left(n m_{0}+b\right)^{2}\right]\left[\left(2 L-r_{\text {Д }}\right)^{2}+4 n^{2} m_{0}^{2}\right]^{\times}} & \\
& \left.\times \frac{\left[\left(r_{\text {Д }}^{2}+4\left(n m_{0}+b\right)^{2}\right]\right.}{\left[\left(2 L-r_{\text {Д }}\right)^{2}+4\left(n m_{0}+b\right)^{2}\right]}\right\}+H_{1 .} .
\end{aligned}
$$

From formula (4), given that $r_{D}<m_{1}$ and $r_{D}<L$, we obtain for the consumption $q=q_{D}$ per unit length of the drainage:

$$
\begin{aligned}
& q_{\text {Д }}=4 \pi r_{1}\left(H_{1}-H_{\text {Д }}\right)\left\{\ln \frac{16 L^{2}\left(L^{2}+b^{2}\right)}{r_{Д}^{2}\left(r_{Д}^{2}+4 b^{2}\right)}+\right. \\
& +\sum_{n=1}^{\infty} c_{n}^{\prime}\left[\ln \left(1+\frac{L^{2}}{\left(n m_{0}-b\right)^{2}}+2 \ln \left(1+\frac{L^{2}}{n^{2} m_{0}^{2}}\right)+\ln \left(1+\frac{L^{2}}{\left(n m_{0}+b\right)^{2}}\right)\right]\right\}^{-1} .
\end{aligned}
$$

In the paper using the theory of O.Oliynyk [16], some partial cases of drainage arrangement in two-layer soil are also considered, in particular at $r_{2}=0$ and $r_{1}=r_{2}$.

For $r_{2}=0$

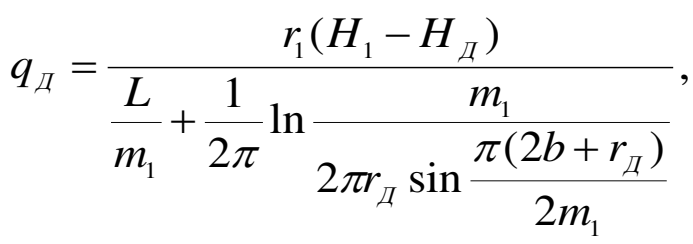




$$
q_{\text {д }}=\frac{r_{1}\left(H_{1}-H_{\text {д }}\right)}{\frac{L}{m_{1}}+\frac{1}{\pi} \ln \frac{m_{1}}{\pi r_{\text {Д }}}} .
$$

To fully intercept the soil flow, a condition is required $H_{\not}^{\prime}=0$, that is, the head over the drain was zero.

$$
H_{\text {д }}^{\prime}=H_{\text {Д }}-\frac{4 \pi r_{1}\left(\frac{4 \pi\left(L^{\prime}-L\right)}{m_{0}}+2 \ln \frac{m_{0}}{4 \pi r_{\text {Д }}^{\prime}}-2 \ln \sin \pi B-2 \ln \frac{\sin \pi B}{4}\right)^{-1}}{q_{\text {Д }}^{\prime}}=0 ;
$$

For the $n$-th drainage, the dependence (8) can be rewritten

$$
H_{\text {Д }}^{n}=H_{Д}^{n-1}-\frac{4 \pi r_{1}\left(\frac{4 \pi\left(L^{n}-L^{n-1}\right)}{m_{0}}+2 \ln \frac{m_{0}}{4 \pi r_{Д}^{n}}-2 \ln \sin \pi B-2 \ln \frac{\sin \pi B}{4}\right)^{-1}}{q_{\text {Д }}^{\prime}}=0 ;
$$

performing the necessary mathematical operations in equation (9) we obtain

$$
\begin{gathered}
H_{\text {Д }}^{\prime}=H_{\text {Д }}-\frac{4 \pi r_{1}\left(\frac{4 \pi\left(L^{\prime}-L\right)}{m_{0}}+2 \ln \frac{m_{0}}{4 \pi r_{Д}^{\prime}}-4 \ln 2\right)^{-1}}{q_{\text {Д }}^{\prime}}=0 ; \\
H_{\text {Д }}^{\prime}=H_{\text {Д }}-\frac{4 \pi r_{1}\left(\frac{4 \pi\left(L^{\prime}-L\right)}{m_{0}}+2 \ln \frac{m_{0}}{16 \pi r_{Д}^{\prime}}\right)^{-1}}{q_{\text {Д }}^{\prime}}=0 ; \\
H_{\text {Д }}^{n}=H_{\text {Д }}^{n-1}-\frac{4 \pi r_{1}\left(\frac{4 \pi\left(L^{n}-L^{n-1}\right)}{m_{0}}+2 \ln \frac{m_{0}}{16 \pi r_{\not}^{n}}\right)^{-1}}{q_{\not}^{n}}=0 ;
\end{gathered}
$$

where $q_{д}^{n}$ - drainage intensity of the nth drainage, $\mathrm{m}^{3} / \mathrm{s}$;

$H_{д}^{n}$ - head over nth drainage, $m$;

$r_{д}^{n}$ - the radius of the cross-section of the nth drainage, $m$;

$L n$-distance from the nth drainage to the power source, $m$;

$b n$-depth of the nth drainage, $m$.

Using the obtained dependencies, the necessary parameters for designing the drainage-collector network along the contour of the phos- 
phogypsum dumps were calculated. The calculation scheme is presented in Fig. 3. For the complete interception of contaminated water drainage will be arranged on the sole of the waterproof layer. In order to prevent contamination of soil and groundwater, the pressure above the drained $H_{D}$ must be equal to 0 . In order to maximally intercept drainage water, the drainage radius should be such that it can pass the drainage flow.

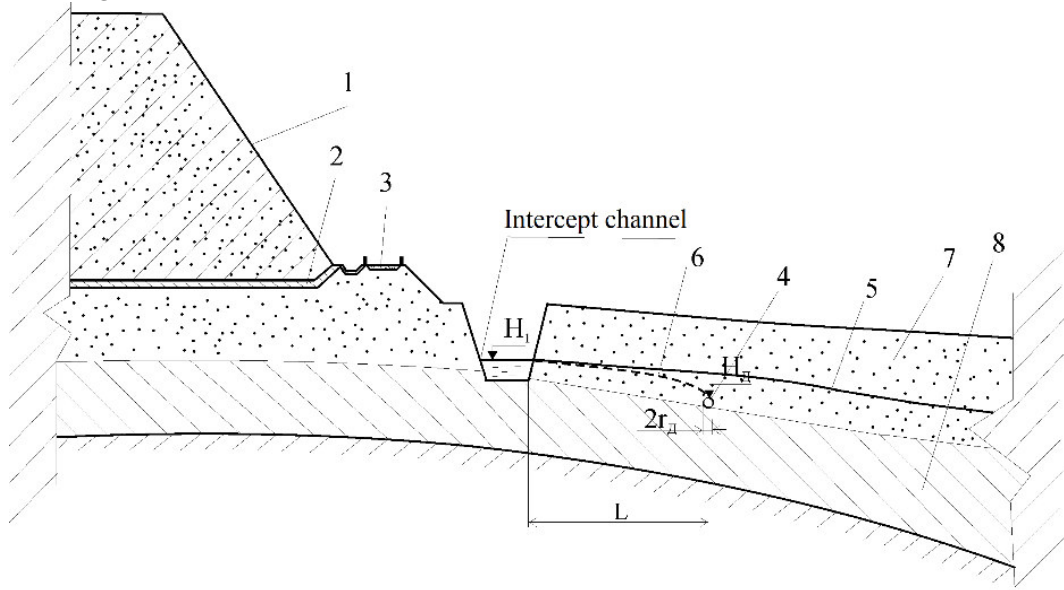

Fig. 3. Scheme for calculating the drainage line device for intercepting soil flow from the array of phosphogypsum dumps: 1 - phosphogypsum dumps; 2 - concrete curtain; 3 - the road; 4 - drainage; 5 - natural groundwater level; 6 - the level of groundwater after drainage; 7 - loops; 8 - loam

For more efficient interception of groundwater, horizontal drainage can be enhanced by vertical wells [17], which will be unloaded into drains (Fig. 4).

Strengthening of drainage by vertical wells is recommended when the soil mass from which contaminated water is removed is represented by soils with low filtration coefficient. 


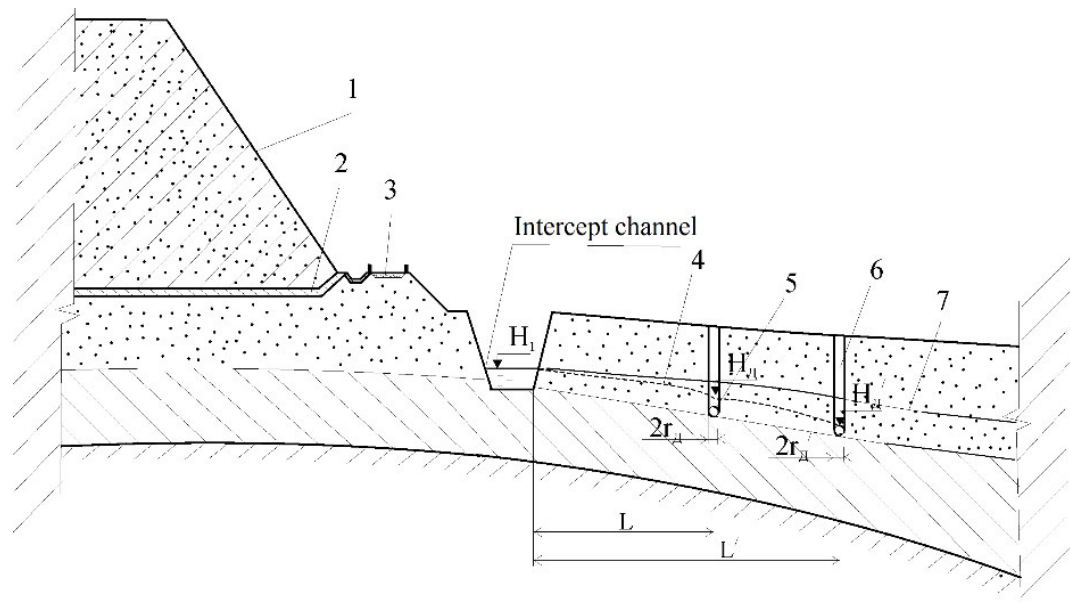

Fig. 4. The scheme of interception of contaminated waters by drainage with reinforced vertical wells: 1 - phosphogypsum dumps; 2 - concrete curtain; 3 - the road; 4 - the level of groundwater after drainage; 5 - drainage; 6 - well; 7 - natural groundwater level

In the construction of tubular drains, as one of the main and defining components of drainage systems, a particularly important step is the arrangement of drainage filters, which provide an increase in the flow of water and reliable protection against siltation. The reliability and durability of drainage systems is mainly determined by the quality of construction and the efficiency of drainage filters [17].

The systematic analysis of the latest research results and the current level of knowledge on the problem of sludge drainage protection indicate that one of the most effective and reliable drainage filters are bulk ready filters made of organic or a mixture of organic and synthetic fibrous materials (production wastes). The main advantages of them compared to thin-layer artificial are: a significant increase in the inflow of water to the drainage, the ability to maintain its protective properties longer due to the less susceptibility to the processes of colmatation (mechanical and hoarding) and the porosity regeneration property, cheapness, availability in sufficient quantity, technological availability, adaptability to soil, environmental friendliness and more. 
Such protective and filtering materials include straw of cereals (wheat, rye, rice, barley, corn), peat, flax, sawdust, chips (especially effective coniferous), textile waste (fibers of cloth, carpet production mainly synthetic). All these materials can be rationally used to protect the drainage from mud.

Coating of phosphogypsum dumps with a protective plastic film, followed by powdering with a fertile soil layer and planting

In the second stage, it is recommended to cover the phosphogypsum dumps with a protective film, followed by powdering the fertile soil layer with the landing of vegetation, which will prevent wind erosion and contamination of adjacent territories [19].

Polymer films as a material for anti-filtration devices of hydraulic structures have several advantages: practical impermeability of the material itself and high resistance of polyethylene and polyvinyl chloride films to aggressive influence of common chemical reagents, high deformative ability of films and high material capacity. The advantages of polymer films should also be attributed to the fact that the formation of water retaining elements in them depends little on the local conditions of construction.

Film anti-filtration devices are reliable in operation throughout the life of the structure. The reliability of operation is determined primarily by the properties of the polymer film element. These properties should provide protection against impacts that are possible during both construction and operational periods.

In our case, not only punctures, cuts, but also changes that would lead to a violation of the integrity of the films and, consequently, a loss of water tightness in the term shorter than the service life of the structure, are inadmissible in film anti-filtration elements.

In the absence of mechanical damage in the film due to its low porosity, water movement through the film is possible only in the form of diffusion of water molecules and soluble substances in it. Diffusion water losses, however, are quite small and in our case acceptable. Soil life of up to 100 years of soil coverage. The vegetation that is recommended for planting on a meter layer of soil - small bushes with sowing grasses.

\section{Recycling phosphogypsum into building materials}

The third stage is designed for a more long-term perspective - the processing of phosphogypsum into building materials [20] (wall 
blocks, overlapping panels, binders with a strength of more than 500 concrete) with simultaneous decontamination of phosphogypsum from harmful elements and removal of rare-earth metals composition of phosphogypsum - up to $1 \%$. Prospects of such works have been proved by both Ukrainian scientists and scientists of other countries. There are currently several phosphogypsum processing technologies for building materials. According to preliminary calculations, the profitability of such production is 5.7 times higher than the standard profitability.

\section{Conclusions}

The result of long-term storage of waste from the production of mineral fertilizers at PJSC "Rivneazot" is the formation of technogenic waste heaps of phosphogypsum, which amount to 15.2 million tons and require a constant increase in the removal of storage areas.

Toxic waste is stored in the dumps, which leads to contamination of soil, surface and groundwater, adversely affecting the health of the population. The main factor that causes soil contamination in the territory of phosphogypsum dumps is the filtration of contaminated water. This is evidenced by soil contamination, which is below the level of groundwater 5 to 10 times higher than on the surface. And over time, this figure increases.

Experimental and field studies have shown that the content of nitrates, chromium, manganese, iron, lead, zinc, copper, cadmium, nickel, cobalt, nitrites and petroleum products in soil and groundwater within the study area exceeds the concentration in all samples.

Recommendations for environmentally safe storage and disposal of phosphogypsum dumps are developed, which include three steps:

- engineering scheme for intercepting contaminated water from the territory of phosphogypsum dumps;

- coating of phosphogypsum dumps with a protective polyethylene film, followed by powdering with a fertile soil layer and planting of vegetation;

- processing of phosphogypsum into building materials.

The paper proposes a method of calculating the drainage-collector network for intercepting highly mineralized water coming from manmade dumps. But the recommendations on the arrangement of the engineering network depending on the soil conditions of the territory of storage of waste of mining or other production are given. 
The complex of measures considered allows to solve the problem of coordination of relations between production, on the one hand, and nature - on the other, will allow to reduce excessive technogenic load on natural objects, to provide protection of soils, ground and surface waters from the receipt of pollution, and will allow to get economic effect from introduction of waste processing technologies.

References

1. Khlopuk M.M., Malanchuk Z.R., Zomiruk R.V. Analysis of the Impact of Point Objects on Soil and Groundwater Contamination in Rivne Region // Coll. of sciences. USUWEE Newsletter. - Rivne: Publisher of USUWEE - 2004. -Vyp. No. 2 (26). - P. 212 - 221.

2. Malanchuk Z.R., Zhomyruk R.V. Research Methods for Determining Soil and Groundwater Contamination by Phosphogypsum Dumps of OJSC "Rivneazot" // Coll. of sciences. Geotechnical Mechanics. - Dnepropetrovsk: IGTM NAS of Ukraine.-2005.-P.121-126.

3. Zhomyruk R.V. Experimental studies of the process of filtration of highly mineralized water through soil mass // Coll. of sciences. USUWEENewsletter. Rivne: Publisher of USUWEE.-2004.- Issue №3 (27) .- P.132-138.

4. Zhomiruk R.V. Investigation of Soil and Groundwater Contamination by Mining Waste // Coll. of sciences. Geotechnical Mechanics. - Dnepropetrovsk: IGTM NAS of Ukraine. - 2012.- №95. - P.133-140.

5. Zhomyruk R.V. Investigation of soil contamination by mining waste // Coll. of sciences. NSU Ave. - Dnepropetrovsk: National Mining University.-2005.P.98-104.

6. Zhomyruk R.V. Influence of environmental pollution on the health of the population in Rivne region // Coll. of sciences. Ave. Newsletter NUWEE.- Rivne: NUWEE.-2005.-Iss. No. 4 (32) .- P.9-16.

7. Evaluation of the content of elements in the storage area of anthropogenic phosphogypsum deposit. Malanchuk Z.R., Vasilchuk O.Y., Zhomiruk R.V. International Scientific and Technical Internet Conference "Innovative Development of Mining", State Enterprise "Krivoy Rig National University" (Kryvyi Rih), 2017.

8. Zhomyruk R.V. Estimation of sorption properties of rocks in the area of mining waste storage // Coll. of sciences. Ave. Newsletter NUWEE.- Rivne: NUWEE.-2006.-Iss. No. 1 (33) .- P.208-213.

9. Zhomyruk R.V., Volkoshovets S.V. Investigation of contamination migration in soils from a local source // Coll. of sciences. ave. "Hydro-reclamation and hydrotechnical construction" .- Rivne: NUWEE. - 2008. - Issue \# 33. - P.127-134.

10. Malanchuk. Z.R., Klepach M.I., Zhomyruk R.V. Investigation of the filtration process of highly mineralized water through soil mass // Coll. of sciences. USUWM Newsletter. - Rivne: Publisher of USUWEE- 2004. -Vyp. No. 2 (26) .- P. $283-290$.

11. Zhomyruk RV, Malanchuk E.Z. Mathematical modeling of the process of soil and groundwater contamination by mining waste // Collected Works. of sciences. etc. Hydroelectric and hydrotechnical construction. - Exactly: NUWEE.2005.-Issue №30.-P.257-262. 
12. Simulation of the process of propagation of pollution by point migration. Zhomyruk R.V, Malenovskaya M. Proceedings of the International Scientific and Practical Conference "Development of National Economies in the Conditions of Globalization" - Rivne, NUWEE, 2012.- P. 49-51

13. Khlopuk M.M, Zhomiruk R.V. Recommendations on the design of drainage structures for the interception of highly mineralized water // Coll. of sciences. USUWEE Newsletter. - Rivne: Publisher of USUWEE-2004.- Issue №3 (27) .P.156-165.

14. Oleynik A. Ya. Geohydrodynamics of drainage. - Kiev: Scientific Thought, 1981. - 284 p.

15. Zhomyruk, R.V. Interception of Soil Flow from the Rivneazot Phosphogypsum Waste Heaps // Zb. of sciences. Ave. Newsletter NUWEE.- Rivne: NUWEE.-2004.-Issue №2 (26) .- P.106-112.

16. Kovalchuk S.V, Oleynik A.Ya. Inflow of water to horizontal tubular drainage in a three-layer head with limited capacity. - Approx. mechanics and techn. physics. - 1996. - №1. - P.129 - 132.

17. Protection of natural complexes from technogenic pollution on the basis of land reclamation measures. Malanchuk Z.R., Rokochinskiy A.M., Zhomiruk R.V. // Abstracts of the Sixth International Scientific-Practical Conference "Topical Issues and Organizational and Legal Foundations of Cooperation between Ukraine and China in the Field of High Technologies" - K:, KievCSTEI, 2009 .- P.120-125.

18. Malanchuk Y.Z., Stets S.E., Zhomyruk R.V, Stets A.S. Modeling of the zeolite-smectite tuffs mining process by hydro-well method // Topical scientific researches into resource-saving technologies in mineral mining and processing. Multiauthored monograph. - Sofia, Bulgaria: St. Ivan Rilski Publishing House, 2020, pp.244-260.

19. Zhomiruk R.V. Recommendations for environmentally friendly exploitation and disposal of mining waste on the example of phosphogypsum waste heaps of JSC Rivneazot // Abstracts of the Sixth Annual Industrial Conference "Efficiency of realization of scientific, resource and industrial potential in modern conditions", Boykivshchyna. - 2006.-P.81-83.

20. Malanchuk Z.P., Moshynskyi V.S, Vasylchuk O.Yu., Zhomyruk R.V. Technological features of processing of man-made waste of phosphogypsum // Sustainable development of resource-saving technologies in mineral mining and processing. Multi-authored monograph. - Petroșani, Romania: UNIVERSITAS Publishing, 2019, pp. 6-18. 